\title{
Mycochemical Screening and Analysis, Antioxidant Activity, and Biochemical Composition of Fermentation Strain Snef1216 (Penicillium chrysogenum)
}

\author{
Aatika Sikandar $\mathbb{D}^{1},{ }^{1}$ Mengyue Zhang, ${ }^{1}$ Yuanyuan Wang, ${ }^{2}$ Xiaofeng Zhu, ${ }^{1}$ Xiaoyu Liu, ${ }^{3}$ \\ Haiyan Fan, ${ }^{1}$ Yuanhu Xuan, ${ }^{4}$ Lijie Chen, ${ }^{1}$ and Yuxi Duan $\left(\mathbb{1}^{1}\right.$ \\ ${ }^{1}$ Nematology Institute of Northern China, Shenyang Agricultural University, Shenyang 110866, Liaoning, China \\ ${ }^{2}$ College of Biosciences and Biotechnology, Shenyang Agricultural University, Shenyang 110866, Liaoning, China \\ ${ }^{3}$ College of Science, Shenyang Agricultural University, Shenyang 110866, Liaoning, China \\ ${ }^{4}$ College of Plant Protection, Shenyang Agricultural University, Shenyang 110866, Liaoning, China
}

Correspondence should be addressed to Yuxi Duan; duanyx6407@163.com

Received 5 December 2019; Revised 26 February 2020; Accepted 6 March 2020; Published 30 March 2020

Academic Editor: Krishna K. Verma

Copyright (c) 2020 Aatika Sikandar et al. This is an open access article distributed under the Creative Commons Attribution License, which permits unrestricted use, distribution, and reproduction in any medium, provided the original work is properly cited.

\begin{abstract}
Antioxidants are the radical scavengers that inhibit peroxidation and other free-radical processes, which in return safeguard different organisms from various diseases attributed to radical reactions. Synthetic antioxidants inhibit free radicals, but they also have harmful side effects. However, mycochemicals of natural fungal origin are safe and best substitutes for harmful synthetic chemical antioxidants. The prime objectives of the study include appropriate qualitative and quantitative mycochemical screening, antioxidant potential, and chemical composition of Snef1216 (Penicillium chrysogenum). The study has used aluminium chloride colourimetric method, Folin-Ciocalteu reagent assay, and DPPH (1,1-diphenyl-1-picrylhydrazyl) for analysis of total flavonoid content and phenol content and antioxidant activity, respectively. However, the presence of biologically active compounds was screened through gas chromatography-mass spectrometry (GC-MS). Quantitative analysis demonstrated the existence of flavonoids, glycosides, flavones, saponins, phenols, and catecholic tannins excluding alkaloids, terpenoids, steroids, and gallic tannins. The outcomes exposed total flavonoid content and phenolic content in P. chrysogenum were $85.31 \pm 1.23 \mathrm{mg} \cdot \mathrm{QE} / \mathrm{g}$ and $135.77 \pm 1.14 \mathrm{mg} \cdot \mathrm{GAE} / \mathrm{g}$, respectively. Snef1216 (P. chrysogenum) displayed the highest free-radical scavenging activity with $63.86 \%$ inhibition of DPPH. The analysis confirms that Snef1216 (P. chrysogenum) is an alternative source of natural antioxidants. The obtained data have provided the foundation for its use in agricultural, environmental, and pharmaceutical industries.
\end{abstract}

\section{Introduction}

Free radicals are associated with numerous chronic and acute diseases in human beings such as asthma, atherosclerosis cataracts, diabetes, liver injury, and neurodegenerative disorder [1]. Antioxidants are useful constituents that are responsible for the inhibition of free radicals by abolishing their target site [2]. They have the capability to capture free radicals such as hydroperoxide and peroxide which constrain oxidation and cause degenerative arrays [3]. Synthetic antioxidants inhibit free radicals and also are have harmful side effects [4]. However, natural resources of mycochemicals are safe and better substitutes for chemical antioxidants [5]. Fungi are an important source of natural antioxidants because of their natural ability to produce secondary metabolites [6]. They contain antioxidants in the form of steroids, quinones, alkaloids, phenylpropanoids, tocopherol, phenols, tannins, lactones, terpenoids, triterpenes carotenoids, and flavonoids [7].

Essential mycochemicals contained in fungi such as phenolic contents have attained more interest due to their characteristics to inhibit disease by their antioxidant activity. Phenols and flavonoids are the major secondary metabolites of fungi [6]. Moreover, phenolic and flavonoids contents of 
fungal origin act as potential therapeutic agents, i.e., antimutagenic, antibiotics, anticarcinogenic, and antioxidants [8]. Fungi belonging to genera Aspergillus, Chaetomium, Creosphaeria, Fusarium, Mucor, Penicillium, Tolypoclaidium, and Xylariaceae showed extraordinary antioxidant potential [9].

Fungi belonging to the genus Penicillium are very common in nature [10]. They are filamentous fungi saprophytic organisms but may also colonize a wide range of materials [11]. They have an important role in bioremediation procedures by decomposition of various xenobiotics [12]. They produce a diversity of primary and secondary metabolites that are mainly owing to the existence of bioactive components such as flavonoids, alkaloids, minerals, proteins, phenols, tannins, vitamins, and antioxidants activities [5].

Penicillium chrysogenum is a common mold and present in almost all ecosystems [13]. Penicillin was the first antibiotic that was isolated from this species, and their biologically active secondary metabolites were the topic of intensive study in recent decades [11]. Many biologically active substances were isolated from $P$. chrysogenum such as tannins, alkaloids, terpenoids, and tannins [6]. It was found that the species of Penicillium produced scavenged DPPH radicals [14]. Penicillenols, secalonic acid D, and atrovenetin were isolated from Penicillium sp. as a potential antioxidant [15].

Strain Snef1216 (Penicillium chrysogenum) was identified by Jiang et al. [16]. Yao et al. [17] and Sikandar et al. [18] reported its efficiency against Meloidogyne incognita (rootknot nematode) in tomato and cucumber, respectively. However, mycochemical analysis and the presence of biologically active compounds have not been properly studied. Therefore, the current study was planned to appraise the presence of mycoconstituents, antioxidant activity, and chemical composition of fermentation strain Snef1216 (Penicillium chrysogenum) at the Nematology Institute of Northern China (NINC), Shenyang Agricultural University, Shenyang, Liaoning, People's Republic of China, during the year 2019.

\section{Materials and Methods}

2.1. Activation of Strain Snef1216 (P. chrysogenum) and Preparation of Fermentation. Fungal strain Snef1216 ( $P$. chrysogenum) was obtained from the China General Microbiological Culture Collection Centre and kept at $-80^{\circ} \mathrm{C}$. To confirm the purity and activation of the strain, a small amount of the strain was added into PDA- (potato dextrose agar-) filled cavities and then kept in an incubator for 7 days at $25-28^{\circ} \mathrm{C}$. The composition of nutritious medium for fermentation: $50 \mathrm{~g}$ sucrose, $8 \mathrm{~g}$ sodium nitrate, $2 \mathrm{~g}$ dipotassium phosphate, $0.4 \mathrm{~g}$ potassium chloride, $0.08 \mathrm{~g}$ magnesium sulfate heptahydrate, and $0.003 \mathrm{~g}$ ferrous sulfate heptahydrate were mixed in $1000 \mathrm{ml}$ distilled water. The consequent mixture was boiled for 5-6 min and then poured $100 \mathrm{ml}$ of medium into a $250 \mathrm{ml}$ flask. The medium was sterilized in a steam autoclave machine (Zealway (Xiamen) Instrument Co., Ltd., Model no. GI54DS) for $30 \mathrm{~min}$ at $121^{\circ} \mathrm{C}$, and five fungus cakes (approximately 1-millimeter diameter each) were added into the $100 \mathrm{ml}$ medium. Then, the resulting mixture was placed in a shaker for 3 days at $150 \mathrm{rpm}$ and $28^{\circ} \mathrm{C}$. After 3 days, $100 \mathrm{ml}$ of the new nutritious medium was added into each flask and then placed in a shaker for 8 days at $150 \mathrm{rpm}$ and $28^{\circ} \mathrm{C}$. Fermentation was filtered and stored at $4^{\circ} \mathrm{C}$ until use [16-18].

2.2. Qualitative Mycochemical Analysis. Qualitative analysis was done to assess the existence of biochemicals in the fermentation strain Snef1216 (P. chrysogenum) by using standard methods.

2.2.1. Glycosides Test. Glycosides' existence was assessed by pouring $3 \mathrm{ml}$ of $5 \%$ ferric chloride $\left(\mathrm{FeCl}_{3}\right)$ and $3 \mathrm{ml}$ distilled water into a $3 \mathrm{ml}$ fermentation solution. After that, the mixture was heated for $15 \mathrm{~min}$ in a water bath. After cooling, $1.5 \mathrm{ml}$ benzene was poured and shaken vigorously for $15 \mathrm{sec}$. The subsequent mixture was allowed to settle down for $1 \mathrm{~min}$ at room temperature. Addition of 5-6 drops of concentrated ammonia $\left(\mathrm{NH}_{3}\right)$ into the mixture resulted in pink colour appearance confirmed the presence of glycosides [19].

2.2.2. Alkaloids Test. Alkaloids were determined by the addition of $3 \mathrm{ml}$ of $2 \%$ hydrochloric acid $(\mathrm{HCl})$ into the dry fermentation, and the mixture was heated at $100^{\circ} \mathrm{C}$ for $15 \mathrm{~min}$ in a water bath. The filtrated mixture was equally poured into two test tubes. 2-4 drops of Dragendoff's reagent were poured into one test tube, whereas 2-4 drops of Mayer's reagent were poured into the second test tube. The existence of alkaloids was determined with the presence of yellow precipitate in the mixture [20].

2.2.3. Flavonoids and Flavones Test. Flavonoids and flavones were assessed by adding $4 \mathrm{ml}$ of diluted sodium hydroxide $(\mathrm{NaOH})$ into the $6 \mathrm{ml}$ fermentation solution, which resulted in the appearance of yellow colour of the mixture. Then, $2 \mathrm{ml}$ $5 \mathrm{~N}$ hydrochloric acid $(\mathrm{HCl})$ was added into the mixture, which made it colourless confirming the existence of flavonoids, while orange colour confirmed flavones [19].

2.2.4. Phenols Test. Presence of phenols was determined according to Ahmed et al. [21]. $3 \mathrm{ml}$ distilled water and 3-4 drops of $10 \%$ ferric chloride $\left(\mathrm{FeCl}_{3}\right)$ were poured into $1.5 \mathrm{ml}$ of the fermentation solution. The appearance of a bluishgreen colour showed the existence of phenols in the mixture; on the other hand, addition of $4 \mathrm{ml}$ of fermentation solution into $6 \mathrm{ml}$ of $10 \%$ lead acetate formed white precipitation, confirming the presence of phenols.

2.2.5. Steroids and Terpenoids Test. For the estimation of steroids and terpenoids, $1 \mathrm{~g}$ of fermentation was dissolved into $4 \mathrm{ml}$ chloroform. The mixture was filtrated and then kept in an icebox. $4 \mathrm{ml}$ of acetic acid and 4-5 drops of $100 \%$ sulphuric acid $\left(\mathrm{H}_{2} \mathrm{SO}_{4}\right)$ were carefully poured into the mixture. The appearance of a pinkish-brown or pink ring 
confirmed the presence of terpenoids, whereas bluish-green or blue colour for steroids existence and the mixture of both colours indicated the existence of terpenoids and steroids [22].

2.2.6. Saponins Test. For the estimation of saponins, $1 \mathrm{~g}$ of fermentation was added into $20 \mathrm{ml}$ distilled water and shaken energetically. The development of $1 \mathrm{~cm}$ foam layer confirmed the existence of saponins [23].

2.2.7. Tannins Test. Tannins existence was assessed by adding $2 \mathrm{ml}$ distilled water and 2-4 drops of concentrated ferric chloride $\left(\mathrm{FeCl}_{3}\right)$ into $1 \mathrm{ml}$ of fermentation solution. Greenish-black or blue colour appearance demonstrated the existence of catecholic and gallic tannins, respectively [23].

\subsection{Quantitative Chemical Analysis}

2.3.1. Determination of Total Flavonoids Content (TFC). Total flavonoids content was assessed by the aluminium chloride colourimetric method using sodium hydroxide $(\mathrm{NaOH})$ and aluminium trichloride $\left(\mathrm{AlCl}_{3}\right)$. Briefly, $2 \mathrm{ml}$ of fermentation solution was poured into $6 \mathrm{ml}$ methanol, with further addition of $10 \mathrm{ml}$ distilled water, $0.2 \mathrm{ml} 1 \mathrm{M}$ potassium acetate $\left(\mathrm{CH}_{3} \mathrm{COOK}\right)$, and $0.4 \mathrm{ml} 10 \%$ aluminium chloride $\left(\mathrm{AlCl}_{3}\right)$ into the mixture. Then the subsequent solution was incubated for $30 \mathrm{~min}$ at room temperature in darkness. Absorbance was calculated at $420 \mathrm{~nm}$ in a 96-well ELISA plate using an "absorbance microplate reader" (SpectraMax 190, designed in USA, manufactured in China). Quercetin was used as the standard $(1 \mathrm{mg} / \mathrm{ml})$ solution in order to obtain the calibration curve using a series of concentrations, i.e., $0,0.01,0.02,0.05,0.10,0.25,0.50$, and $1 \mathrm{mg} / \mathrm{ml}$. Total flavonoid content was calculated from the calibration curve by using linear regression equation $\left(Y=-0.004 x+0.053 ; R^{2}=0.995\right)$. Consequences were shown as quercetin equivalent (QE) $\mathrm{mg} / \mathrm{g}$ of fermentation. The experiment was performed in triplicate [24].

\subsubsection{Determination of Total Phenolic Content (TPC).}

Total phenol content was calculated by using Folin-Ciocalteu reagent procedure with minor alterations. $2 \mathrm{ml}$ fermentation solution was added to $4 \mathrm{ml}$ of $2 \%$ sodium carbonate $\left(\mathrm{Na}_{2} \mathrm{CO}_{3}\right)$ and $5 \mathrm{ml}$ of $10 \%$ Folin-Ciocalteu reagent. The subsequent solution was incubated for $15 \mathrm{~min}$ at room temperature in darkness. Then, to quantify absorbance at $765 \mathrm{~nm}$, the resulting mixture was poured into a 96-well ELISA plate. The standard curve was made by gallic acid $(1 \mathrm{mg} / \mathrm{ml})$. Outcomes were measured through the standard curve achieved by a series of gallic acid concentrations ( 0 , $0.01,0.02,0.05,0.10,0.25,0.50$, and $1 \mathrm{mg} / \mathrm{ml}$ ). The phenolic content was calculated from the calibration curve by using linear regression equation $\left(Y=-0.005 x+0.053 ; R^{2}=0.998\right)$. Consequences are determined as gallic acid equivalent (GAE) $\mathrm{mg} / \mathrm{g}$ of compounds. The experiment was performed in triplicate [24].
2.3.3. Determination of DPPH Radical Scavenging Activity. Antioxidant activity was calculated on the basis of the scavenging activities of DPPH radical (1,1-diphenyl-1-picrylhydrazyl). $0.5 \mathrm{ml}$ of fermentation solution was added into freshly prepared $3.5 \mathrm{ml}$ of DPPH methanolic solution $(0.004 \mathrm{~g} / 100 \mathrm{ml})$. The mixture was incubated for $30 \mathrm{~min}$ at room temperature in darkness and was poured into a 96-well ELISA plate to observe the absorbance at $517 \mathrm{~nm}$. Percentage of inhibition of DPPH was measured by the reduction of absorbance by using the following equation. A less absorbance indicates more free radical scavenging potential or vice versa [25].

$$
\text { Inhibition percent }(I \%)=\frac{A_{\text {blank }}-A_{\text {sample }}}{A_{\text {blank }}} \times 100,
$$

where $A_{\text {blank }}$ is absorbance in the control and $A_{\text {sample }}$ is absorbance in the sample.

2.4. Preparation of Sample for Gas Chromatography-Mass Spectrophotometry (GC-MS). Fermentation was prepared for Gas chromatography-mass spectrometry as previously described in a procedure by Popova et al. [26] with minor modifications. $0.05 \mathrm{~g}$ of dry fermentation was dissolved into $5 \mathrm{ml}$ of methanol HPLC grade. $200 \mu \mathrm{L}$ of the subsequent solution was mixed with $800 \mu \mathrm{L}$ of methanol for further dilution to make $1 \mathrm{ml}$ and poured into a $1.5 \mathrm{ml}$ centrifuge tube.

2.5. Gas Chromatography-Mass Spectrophotometry Analysis. Fermentation was analyzed by GC-MS using Agilent 6890$5973_{\mathrm{N}}$, USA. Gas chromatography (GC) equipped with an HP1 TG-5MS polydimethylsiloxane capillary column $(30 \mathrm{~m} \times 250 \mu \mathrm{m} \times 0.25 \mu \mathrm{m})$ interfaced with a Hewlett Packard 5973 mass selective detector. Parameters were fixed; $70^{\circ} \mathrm{C}$ was the initial temperature extended up to $220^{\circ} \mathrm{C}$ at an increase rate of $10^{\circ} \mathrm{C}$ per min. However, the inlet temperature was $250^{\circ} \mathrm{C}$, split ratio $10: 1$, MS quadruple temperature $150^{\circ} \mathrm{C}$, thermal Aux temperature $285^{\circ} \mathrm{C}$, MS scan temperature 35-520 units, and ionization energy $70 \mathrm{eV}$; as a carrier gas, helium was used at a flow rate of $1.0 \mathrm{ml} / \mathrm{min}^{-1}$. Compounds were identified by construal on GC-MS mass spectrum by using the literature data or database at Wiley/ NIST.98.1 [27]. The comparative yield of each compound was assessed based on raw data areas of GC with no response factor correction of FID (flame ionization detection).

2.6. Statistical Analysis. All data were statistically analyzed by using one-way ANOVA (analysis of variance) in Duncan's multiple range test $(p=0.05)$. All statistical analyses weres performed by using IBM-SPSS software (version 25.0).

\section{Results and Discussion}

3.1. Qualitative Mycochemical Analysis. Tests for chemical screening showed the existence of bioactive compounds, i.e., glycosides, phenols, flavonoids, flavones, saponins, and tannins in the fermentation of Snef1216 ( $P$. chrysogenum) (see Table 1). The estimation of compounds was denoted as 
TABLE 1: Qualitative analysis of mycochemicals in the fermentation strain Snef1216 (P. chrysogenum) and nutritious medium.

\begin{tabular}{lcc}
\hline $\begin{array}{l}\text { Mycochemical } \\
\text { constituents }\end{array}$ & $\begin{array}{c}\text { Snef1216 } \\
(\text { P. chrysogenum })\end{array}$ & $\begin{array}{c}\text { Nutritious } \\
\text { medium }\end{array}$ \\
\hline Glycosides & + & - \\
Alkaloids & - & - \\
Flavonoids & ++ & + \\
Flavones & + & + \\
Phenols & ++ & - \\
Terpenoids & - & - \\
Steroids & - & - \\
Saponins & + & - \\
Catecholic tannins & + & - \\
Gallic tannins & - & - \\
\hline
\end{tabular}

maximum existence $(++)$ due to more similarity; moderate existence $(+)$ due to average or weak and (-) without any similarity or alteration of colour of the reaction mixture. The detection of glycosides was determined by the appearance of pink colour. Green or blue colour showed the existence of phenols in the mixture. The detection of flavones and flavonoids was confirmed by the alteration of yellow reaction mixture into orange or colorless, respectively. The existence of saponins in the mixture was determined by the formation of a foaming layer in the solution. The appearance of black or green colour confirmed the presence of catecholic tannins.

The results of qualitative tests for chemical screening showed a moderate presence of glycosides while alkaloids were absent in P. chrysogenum. Besides, phenols and flavonoids highly existed, whereas flavones were moderately present. Qualitative chemical screening of fermentation revealed that steroids and terpenoids were absent, while a moderate presence of saponins and catecholic tannins was recorded. However, gallic tannins were not recorded during chemical screening. The chemical analysis of the nutritious medium displayed only a moderate presence of phenols and flavonoids.

Antioxidants are the key substances that possess defensive nature against damage posed by the free radicals that become a cause of induced oxidative stress. Mycochemicals or secondary metabolites are occurring naturally in fungi which are an essential source of natural antioxidants that possess curative, protective, and defensive potential [28]. These mycochemicals can play a useful role in several mechanisms such as transforming hydroperoxides into nonradical species, scavenging oxygen, binding of metallic ions, and neutralizing singlet oxygen or absorbing ultraviolet radiation [29]. Essential mycochemicals contained in fungi have attained more attention due to their characteristics to inhibit disease by their antioxidant activity.

Mycochemical screening exposed the existence of chemical constituents, i.e., glycosides, alkaloids, phenols, flavonoids, terpenoids, flavones, steroids, tannins, and saponins. Terpenoids are used as anti-inflammatory and anticancer agents and contain leishmanicidal and trypanocidal activities [30]. Tannins exhibit antibacterial, antitumor, and antiviral activities [10]. Alkaloids display a wide range of activities such as antitumor, antihypertensive, antidepressant, anticholinergic, myorelaxant, anti-inflammatory, sympathomimetic, antitussigen, hypnoanalgesic, diuretic, antitumor, emetic, and antimicrobial [31].

Our results agree with Jakovljević et al. [10] that terpenoids, alkaloids, flavonoids, and phenols are present in $P$. cyclopium and P. brevicompactum. Mycochemical screening of $P$. frequentans showed the existence of chemical constituents, i.e., terpenoids, phenols, saponins, tannins, flavonoids, and alkaloids while steroids were absent [32]. Aspergillus sp. JPY1, Phoma sp., and P. chrysogenum displayed the existence of terpenes, tannins, sterols, and flavonoids [4]. This study demonstrated that the qualitative mycochemical screening of Snef1216 (P. chrysogenum) exhibited vital bioactive chemical constituents.

\subsection{Quantitative Mycochemical Analysis}

3.2.1. Total Flavonoids Content (TFC). The total amount of flavonoids contents was calculated through the standard curve using serial concentrations of quercetin, namely, 0 , $0.01,0.02,0.05,0.10,0.25,0.50$, and $1 \mathrm{mg} / \mathrm{ml}$. The total flavonoids contents of $P$. chrysogenum and nutritious medium are presented in Table 2. The flavonoids contents of $P$. chrysogenum and nutritious medium were $85.31 \pm 1.23$ and $1.43 \pm 1.33 \mathrm{mg}$ quercetin equivalent $\mathrm{QE} / \mathrm{g}$, respectively. The nutritious medium displayed fewer flavonoid contents as compared to fermentation strain Snef1216 (P. chrysogenum).

Flavonoids are the major secondary metabolites of fungi $[33,34]$. They are polyphenolic compounds recognized because of their antioxidant properties and free-radical scavenging potential [35]. They act as potential therapeutic agents such as antiviral, antiherbivore, antipyretic, antiulcerogenic, antimutagenic, antitumor, antibacterial, antibiotic, antiprotozoal, anticarcinogenic, antinociceptive, and antiinflammatory activities and antioxidants [36]. Bhardwaj et al. [32] described that flavonoids content was present in $P$. frequentans $(17.48 \mathrm{mg} / \mathrm{g})$, Alternaria alternate $(17.41 \mathrm{mg} / \mathrm{g})$, Thielaviopsis basicola (17.41 mg/g), and Geotrichium albida (17.41 mg/g). Nutritious medium displayed fewer flavonoid contents as compared to fermentation strain Snef1216 ( $P$. chrysogenum). Mostly, the enrichment of antioxidants takes place during the fermentation because of the linkage between the breakdown of flavonoid compounds and microorganisms [37]. Additionally, fermentation prompts the structural breakdown of large and complex molecules which lead to the release or synthesis of various antioxidant compounds $[38,39]$. Our study indicates that Snef1216 (P. chrysogenum) is an important source of flavonoid compounds.

3.2.2. Total Phenolic Content (TPC). The total amount of phenolic content was measured through a standard curve using serial concentrations of gallic acid $(0,0.01,0.02,0.05$, $0.10,0.25,0.50$, and $1 \mathrm{mg} / \mathrm{ml})$. The total phenolic contents of $P$. chrysogenum and nutritious medium were presented (Table 2) as $135.77 \pm 1.14$ and $3.68 \pm 0.96 \mathrm{mg}$ gallic acid equivalent GAE/g, respectively. However, a nutritious medium showed very less phenolic content as compared to fermentation strain Snef1216 ( $P$. chrysogenum). During 
TABLE 2: Total flavonoids contents, total phenolic contents, and DPPH radical scavenging activity of fermentation of Snef1216 (P. chrysogenum) and nutritious medium.

\begin{tabular}{lccc}
\hline Quantitative analysis & Total flavonoids contents $(\mathrm{mg} \cdot \mathrm{QE} / \mathrm{g})$ & Total phenolic contents (mg.GAE/g) & DPPH inhibition (\%) \\
\hline \multirow{2}{*}{ Snef1216 nutritious medium } & $85.31 \pm 1.23$ & $135.77 \pm 1.14$ & $63.86 \pm 0.82$ \\
& $1.43 \pm 1.33$ & $3.68 \pm 0.96$ & $0 \pm 0$ \\
\hline & $\mathrm{S} . \mathrm{S}=8637.65$ & $\mathrm{~S} . \mathrm{S}=18848.02$ & $\mathrm{~S} . \mathrm{S}=2885.37$ \\
Statistical summary & $\mathrm{D} f=1, p=0.000$ & $\mathrm{D} f=1, p=0.000$ & $\mathrm{D} f=1, p=0.000$ \\
& $\mathrm{M} . \mathrm{S}=8637.65$ & $\mathrm{M} . \mathrm{S}=18848.02$ & $\mathrm{M} . \mathrm{S}=2885.37$ \\
& $F=5273.10$ & $F=16948.30$ & $F=8527.20$ \\
\hline
\end{tabular}

Values are presented in the table as mean \pm standard deviation. S.S, sum of square; M.S, mean square; $D f$, degree of freedom; $F, F$ value; $p$, significant value.

fermentation, bioactive compounds may be produced through secondary metabolic pathways or released from the substrate by enzymes produced through microorganisms [40].

Phenolic compounds derived from fungi showed antioxidant properties by stopping the conversion of hydroperoxides into nonradicals or deactivating lipid free radicals [41]. The present study revealed that the high amount of phenolic content was recorded in fermentation of Snef1216 (P. chrysogenum). In comparison, a nutritious medium showed very few phenolic contents. However, our results were contradictory to Jakovljević et al. [6] who reported that $P$. chrysogenum had a lower content of total phenols (2.859 mg.GAE/g) than of $P$. fumiculosum (2.109 mg.GAE/g). The amount of total phenolic content in P. chrysogenum was $15.45 \mathrm{mg} \cdot \mathrm{GAE} / \mathrm{g}$ [42]. During the present study, the higher amount of phenolic content was recorded in the fermentation of $P$. chrysogenum. Similarly, earlier researchers have observed that fermentation can efficiently enhance the phenolic content of any tested materials [43-45]. Basically, these enhancements in total phenolic contents were due to microorganisms which involved in fermentation [46, 47]. Snef1216 (P. chrysogenum) may attain as an important source of phenolic compounds, contributing a better choice for the production of natural antioxidants.

3.2.3. DPPH (1,1-Diphenyl-1-Picrylhydrazyl) Radical Scavenging Activity. DDPH (1,1-diphenyl-1-picrylhydrazyl) is a free and stable radical which displayed colour absorption at $517 \mathrm{~nm}$. These radicals can be scavenged by the different types of antioxidant molecules because these radicals can easily donate their hydrogen molecules, and as a result, colour of the solution of DPPH (1,1-diphenyl-1-picrylhydrazyl) turns into light yellow initiating decrease in absorbance. DPPH radicals are widely used for the assessment of radical scavenging activities. Table 2 represents the DPPH scavenging activity of the fermentation strain Snef1216 (P. chrysogenum) and nutritious medium. DPPH inhibition (\%) of Snef1216 (P. chrysogenum) was recorded as $63.86 \pm 0.82$. Moreover, the nutritious medium displayed no DPPH radical scavenging activity.

Outcomes of DPPH scavenger action studies showed that the percentage inhibition of DPPH was $51.34 \%$ in P. fumiculosum and $37.42 \%$ in P. chrysogenum [6], while during the present study, DPPH inhibition (\%) of Snef1216
(P. chrysogenum) was recorded as $63.859 \pm 0.823$. It has been reported in the previous study that DPPH radical scavenging ability was significantly enhanced by fermentation [48]. Chomcheon et al. [49] demonstrated that Aspergillus niger exhibited notable antioxidant compounds during fermentation. Our finding indicates that Snef1216 (P. chrysogenum) may accomplish as a natural antioxidant agent.

3.3. Gas Chromatography-Mass Spectrometry Analysis. The existence of biologically active compounds in Snef1216 (P. chrysogenum) was screened through conducting GC-MS analysis. The principal compound, peak area (\%), retention time (R.T), and molecular formula (M.F) with their molecular weight $\mathrm{g} / \mathrm{mol}$ (M.W) are presented in Table 3. The results pertaining to GC-MS analysis of fermentation of Snef1216 showed the presence of ten compounds corresponding to $100 \%$ of total fermentation. However, benzoic acid, 2-methoxy-, methyl ester (23.51\%), hexadecanoic acid, methyl ester (18.68\%), undecane (11.94\%), isopropyl myristate $(11.66 \%)$, and oxime-, methoxy-phenyl $(9.22 \%)$ were the major compounds while others were recorded in low quantity with the peak value ranged from $3.83-5.78 \%$. The chromatogram obtained by GC-MS analysis detected different peaks of compounds (see Figure 1).

These biologically active compounds are accountable for antioxidant activities. Baert [50] reported that benzoic acid, 2methoxy-, methyl ester, or ortho-anisic acid can be used as a nonsteroidal anti-inflammatory drugs. Oxime-, methoxyphenyl, and hexadecanoic acid possess antioxidant and antimicrobial behaviour [51, 52]. The compounds cyclotrisiloxane, hexamethyl, and isopropyl myristate have the antioxidant potential $[53,54]$. Undecane has a broad spectrum of antimicrobial activities [55]. Benzoic acid methyl ester displayed repellent potential towards insects such as Bemisia tabaci [56]. Chen et al. [57] also reported that methyl benzoate has insecticidal properties against pest insects and mites. Save et al. [58] reported that 1, 2-benzenedicarboxylic acid, butyl octyl ester, can be used in drug development for arthritis, microbial allergies, and cancer, whereas it can also be used as an antioxidant and antimicrobial agent [59]. 8Octadecenoic acid methyl ester (E) showed antioxidant and antimicrobial activity and also effects of the serum lipid in women during lactation period [60, 61]. Merlin et al. [62] reported that heptadecanoic acid, 16-methyl, methyl ester possess anti-inflammatory, antimicrobial, and antioxidant properties. Almost all compounds contained in Snef1216 
TABLE 3: Biochemical composition of fermentation of Snef1216 (P. chrysogenum).

\begin{tabular}{|c|c|c|c|c|c|}
\hline P. no. & R.T & Compounds & Area $(\%)$ & M.F & M.W $\left(\mathrm{gmol}^{-1}\right)$ \\
\hline 1 & 3.876 & Benzoic acid, 2-methoxy-, methyl ester & 23.51 & $\mathrm{C}_{6} \mathrm{H}_{10} \mathrm{O}_{3}$ & 166.17 \\
\hline 2 & 4.448 & Oxime-, methoxy-phenyl & 9.22 & $\mathrm{C}_{8} \mathrm{H}_{9} \mathrm{NO}_{2}$ & 151.16 \\
\hline 3 & 7.643 & Cyclotrisiloxane, hexamethyl & 3.83 & $\mathrm{C}_{6} \mathrm{H}_{18} \mathrm{O}_{3} \mathrm{Si}_{3}$ & 222.46 \\
\hline 4 & 9.043 & Undecane & 11.94 & $\mathrm{C}_{11} \mathrm{H}_{24}$ & 156.31 \\
\hline 5 & 9.298 & Benzoic acid, methyl ester & 5.78 & $\mathrm{C}_{6} \mathrm{H}_{5} \mathrm{COOCH}_{3}$ & 136.15 \\
\hline 6 & 37.043 & Isopropyl myristate & 11.66 & $\mathrm{C}_{17} \mathrm{H}_{34} \mathrm{O}_{2}$ & 270.5 \\
\hline 7 & 40.415 & Hexadecanoic acid, methyl ester & 18.68 & $\mathrm{C}_{17} \mathrm{H}_{34} \mathrm{O}_{2}$ & 270.45 \\
\hline 8 & 41.654 & 1, 2-Benzenedicarboxylic acid, butyl octyl ester & 4.49 & $\mathrm{C}_{20} \mathrm{H}_{30} \mathrm{O}_{4}$ & 333.45 \\
\hline 9 & 45.865 & 8-Octadecenoic acid, methyl ester (E) & 5.45 & $\mathrm{C}_{19} \mathrm{H}_{36} \mathrm{O}_{2}$ & 296.5 \\
\hline 10 & 46.687 & Heptadecanoic acid, 16-methyl-, methyl ester & 5.44 & $\mathrm{C}_{19} \mathrm{H}_{38} \mathrm{O}_{2}$ & 298.50 \\
\hline
\end{tabular}

P. no., peak number; R.T, retention time; M.F, molecular formula; M.W, molecular weight.

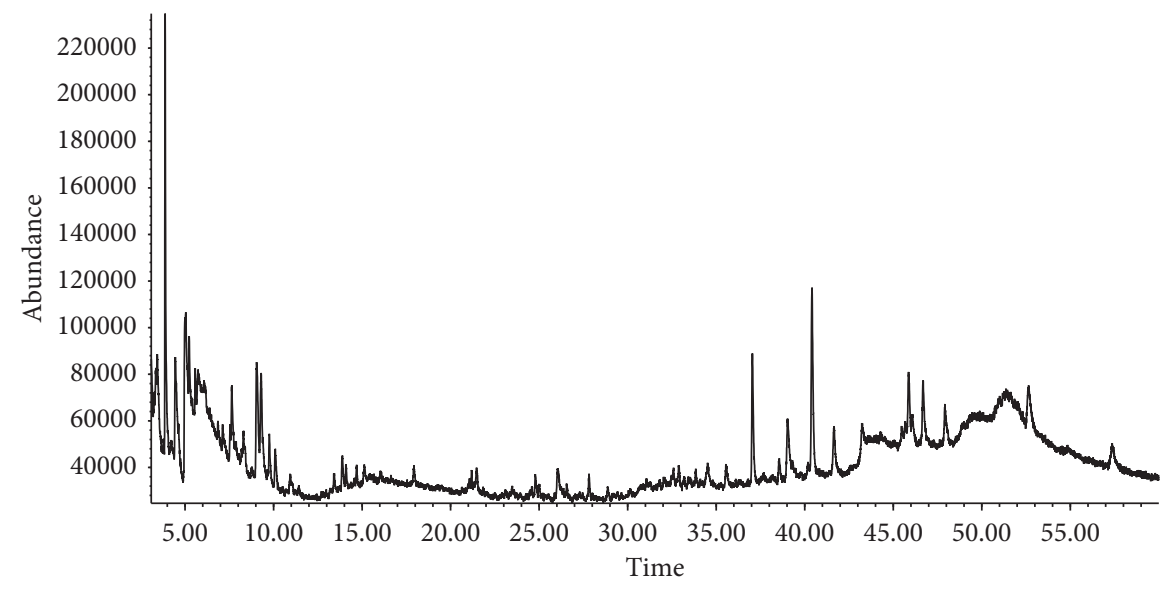

FIgURE 1: Biochemical composition of fermentation of Snef1216 (P. chrysogenum).

(P. chrysogenum) are important from the pharmacological and agricultural viewpoint.

\section{Conclusion}

Based on the outcome of the present study, it was concluded that fermentation strain Snef1216 ( $P$. chrysogenum) comprised of a numerous secondary metabolites; flavonoids and phenols confer to free-radical scavenging activities. It could be an effective and safe source of natural antioxidant. Mycochemical screening revealed the existence of ten biologically active compounds responsible for the antioxidant activity of Snef1216 (P. chrysogenum). The present study provides the basis for the use of Snef1216 (P. chrysogenum) as natural antioxidant agent. However, further studies are desired to explore the role of mycochemicals accountable for the antioxidant activity of Snef 1216 for its commercial use in the agricultural and pharmaceutical industry.

\section{Data Availability}

All the data supporting the current findings reported in this manuscript are available within the manuscript and not attached as any supplementary file.

\section{Conflicts of Interest}

The authors have no conflicts of interest.

\section{Acknowledgments}

This work was supported by the Special Fund for Agroscientific Research in the Public Interest (201503114) and China Agriculture Research System (CARS-04-PS13).

\section{References}

[1] Z. Liu, Z. Ren, J. Zhang et al., "Role of ROS and nutritional antioxidants in human diseases," Frontiers in Physiology, vol. 9, 2018.

[2] S.-i. Yamagishi and T. Matsui, "Nitric oxide, a janus-faced therapeutic target for diabetic microangiopathy-Friend or foe?" Pharmacological Research, vol. 64, no. 3, pp. 187-194, 2011.

[3] Y.-y. Wu, W. Li, Y. Xu, E.-h. Jin, and Y.-y. Tu, "Evaluation of the antioxidant effects of four main theaflavin derivatives through chemiluminescence and DNA damage analyses," Journal of Zhejiang University SCIENCE B, vol. 12, no. 9, pp. 744-751, 2011.

[4] S. Dhankhar, S. Kumar, S. Dhankhar, and J. Yadav, "Antioxidant activity of fungal endophytes isolated from Salvadora oleoides decne," International Journal of Pharmacy and Pharmaceutical Sciences, vol. 4, no. 2, pp. 380-385, 2012.

[5] M. A. Tajick, H. S. M. Khani, and V. Babaeizad, "Identification of biological secondary metabolites in three Penicillium species, $P$. goditanum, $P$. moldavicum, and $P$. corylophilum," Progress in Biological Sciences, vol. 4, no. 1, pp. 53-61, 2014. 
[6] V. Jakovljevic, J. Milicevic, J. Stojanovic, S. Solujic, and M. Vrvic, "Antioxidant activity of ethanolic extract of Penicillium chrysogenum and Penicillium fumiculosum," Chemical Industry, vol. 68, no. 1, pp. 43-49, 2014.

[7] T. Sajeesh, K. Arunachalam, and T. Parimelazhagan, "Antioxidant and antipyretic studies on Pothos scandens L," Asian Pacific Journal of Tropical Medicine, vol. 4, no. 11, pp. 889899, 2011.

[8] S. Kusari, S. P. Pandey, and M. Spiteller, "Untapped mutualistic paradigms linking host plant and endophytic fungal production of similar bioactive secondary metabolites," Phytochemistry, vol. 91, pp. 81-87, 2013.

[9] N. Murthy, K. Poshpalatha, and C. Joshi, “Antioxidant activity of endophytic fungus Phillosticta sp. isolated from Guazuma tomentosa," Journal of Chemical Research, vol. 3, pp. 218-225, 2011.

[10] V. D. Jakovljević, J. M. Nikolić, S. L. Matić, S. M. Stanić, and M. M. Vrvić, "Mycochemical screening, antioxidant and DNA protecting activity of Penicillium cyclopium and Penicillium brevicompactum," FARMACIA, vol. 66, no. 3, pp. 494-501, 2018.

[11] B. M. Onyegeme-Okerenta and O. A. T. Ebuehi, "Physiological effect of natural penicillin extract on cassava peel media by Penicillium chrysogenum PCL501 on E. coli infected wistar rats," IOSR Journal of Pharmacy (IOSRPHR), vol. 7, no. 4, pp. 34-42, 2017.

[12] R. Singh and R. S. Majumdar, "Comparative study on bioremediation for oil spills using microbes," Research and Reviews: A Journal of Bioinformatics, vol. 4, no. 1, pp. 16-24, 2017.

[13] P. Devi, L. D'Souza, T. Kamat, C. Rodrigues, and C. G. Naik, "Batch culture fermentation of Penicillium chrysogenum and a report on the isolation, purification, identification and antibiotic activity of citrinin," Indian Journal of Marine Sciences, vol. 38, pp. 38-44, 2009.

[14] M. A. Dhale, S. Divakar, S. Umesh-Kumar, and G. Vijayalakshmi, "Characterization of dehydromonacolinMV2 from Monascus purpureus mutant," Journal of Applied Microbiology, vol. 103, no. 6, pp. 2168-2173, 2007.

[15] Z.-J. Lin, Z.-Y. Lu, T.-J. Zhu, Y.-C. Fang, Q.-Q. Gu, and W.-M. Zhu, "Penicillenols from Penicillium sp. GQ-7, an endophytic fungus associated with Aegiceras corniculatum," Chemical \& Pharmaceutical Bulletin, vol. 56, no. 2, pp. 217221, 2008.

[16] M. Jiang, Y. Duan, L. Chen, and X. Zhu, "Study on the fermentation of Penicillium Snef1216 inducing the resistance of tomato to root-knot nematode," Journal of Henan Agricultural Sciences, vol. 40, pp. 104-108, 2011.

[17] Q. Yao, X. Lu, X. Zhu, Y. Wang, L. Chen, and Y. Duan, "Resistance against Meloidogyne incognita in tomato induced by fermentation liquid of Penicillium chrysogenum strain 1216," Acta Phytopathologica Sinica, vol. 44, pp. 693-699, 2014.

[18] A. Sikandar, M. Y. Zhang, X. F. Zhu et al., "Effects of Penicillium chrysogenum strain Snef1216 against root-knot nematodes (Meloidogyne incognita) in cucumber (Cucumis sativus L.) under greenhouse conditions," Applied Ecology and Environmental Research, vol. 17, pp. 12451-12464, 2019.

[19] S. Siddiqui, A. Verma, A. A. Rather, F. Jabeen, and M. K. Meghvansi, "Preliminary phytochemicals analysis of some important medicinal and aromatic plants," Advances in Biological Research, vol. 3, pp. 188-195, 2009.

[20] M. S. Auwal, S. Saka, I. A. Mairiga, K. A. Sanda, A. Shuaibu, and A. Ibrahim, "Preliminary phytochemical and elemental analysis of aqueous and fractionated pod extracts of Acacia nilotica (Thorn mimosa)," Veterinary Research Forum: An International Quarterly Journal, vol. 5, no. 2, pp. 95-100, 2014.

[21] M. Ahmed, M. Ji, P. Qin et al., "Phytochemical screening, total phenolic and flavonoids contents and antioxidant activities of Citrullus colocynthis L. and Cannabis sativa L," Applied Ecology and Environmental Research, vol. 17, no. 3, pp. 6961-6979, 2019.

[22] S. Awala and V. Oyetayo, "Molecular identity and antimicrobial profile of trametes species collected from the teaching and research farm of the federal university of technology, Akure, Nigeria," Journal of Advances in Medical and Pharmaceutical Sciences, vol. 4, no. 3, pp. 1-14, 2015.

[23] V. Devmurari, "Phytochemical screening study and antibacterial evaluation of Symplocos racemosa Roxb," Archives of Applied Science Research, vol. 2, no. 1, pp. 354-359, 2010.

[24] O. A. Aiyegoro and A. I. Okoh, "Preliminary phytochemical screening and in vitro antioxidant activities of the aqueous extract of Helichrysum longifolium DC," BMC Complementary and Alternative Medicine, vol. 10, p. 21, 2010.

[25] H. Zhao, W. Fan, J. Dong et al., "Evaluation of antioxidant activities and total phenolic contents of typical malting barley varieties," Food Chemistry, vol. 107, no. 1, pp. 296-304, 2008.

[26] M. Popova, S. Silici, O. Kaftanoglu, and V. Bankova, "Antibacterial activity of turkish propolis and its qualitative and quantitative chemical composition," Phytomedicine, vol. 12, no. 3, pp. 221-228, 2005.

[27] W. Xiaoli, K. Imhoi, K. Seongho, and Z. Xiang, "Compound identification in GC-MS by simultaneously evaluating the mass spectrum and retention index," The Analyst, vol. 139, no. 10, pp. 2507-2514, 2014.

[28] P. Devi, C. Rodrigues, C. G. Naik, and L. D'Souza, "Isolation and characterization of antibacterial compound from a mangrove-endophytic fungus, Penicillium chrysogenum MTCC 5108," Indian Journal of Microbiology, vol. 52, no. 4, pp. 617-623, 2012.

[29] M. Gordon, J. Pokorny, and N. Yanishlieva, "The development of oxidative rancidity in foods," in Antioxidants in Food: Practical Applications, J. Pokorny, N. Yanishlieva, and M. Gordon, Eds., CRC Press, Boca Raton, FL, USA, 2001.

[30] V. P. Sülsen, S. I. Cazorla, F. M. Frank et al., "Natural terpenoids from Ambrosia species are active in vitro and in vivo against human pathogenic trypanosomatids," PLoS Neglected Tropical Diseases, vol. 7, no. 10, Article ID e2494, 2013.

[31] A. L. Souto, J. F. Tavares, M. S. Da Silva, M. d. F. F. M. Diniz, P. F. de Athayde-Filho, and J. M. Barbosa Filho, "Antiinflammatory activity of alkaloids: an update from 2000 to 2010," Molecules, vol. 16, no. 10, pp. 8515-8534, 2011.

[32] A. Bhardwaj, D. Sharma, N. Jadon, and P. Agrawal, "Antimicrobial and phytochemical screening of endophytic fungi isolated from spikes of Pinus roxburghii," Archives of Clinical Microbiology, vol. 6, pp. 1-9, 2015.

[33] E. M. Heider, J. K. Harper, D. M. Grant et al., "Exploring unusual antioxidant activity in a benzoic acid derivative: a proposed mechanism for citrinin," Tetrahedron, vol. 62, no. 6, pp. 1199-1208, 2006.

[34] R. Y. Nsimba, H. Kikuzaki, and Y. Konishi, "Antioxidant activity of various extracts and fractions of Chenopodium quinoa and Amaranthus spp. seeds," Food Chemistry, vol. 106, no. 2, pp. 760-766, 2008.

[35] R. Scherer and H. T. Godoy, "Antioxidant activity index (AAI) by the 2,2-diphenyl-1-picrylhydrazyl method," Food Chemistry, vol. 112, no. 3, pp. 654-658, 2009.

[36] T. Mitrović, S. Stamenković, V. Cvetković et al., "Antioxidant, antimicrobial and antiproliferative activities of five lichen 
species," International Journal of Molecular Sciences, vol. 12, no. 8, pp. 5428-5448, 2011.

[37] F. O. Adetuyi and T. A. Ibrahim, "Effect of fermentation time on the phenolic, flavonoid and vitamin $\mathrm{C}$ contents and antioxidant activities of okra (Abelmoschus esculentus) seeds," Nigerian Food Journal, vol. 32, no. 2, pp. 128-137, 2014.

[38] S. J. Hur, S. Y. Lee, Y.-C. Kim, I. Choi, and G.-B. Kim, "Effect of fermentation on the antioxidant activity in plant-based foods," Food Chemistry, vol. 160, pp. 346-356, 2014.

[39] M. Verni, V. Verardo, and C. G. Rizzello, "How fermentation affects the antioxidant properties of cereals and legumes," Foods, vol. 8, no. 9, p. 362, 2019.

[40] C. L. Handa, F. S. de Lima, M. F. G. Guelfi, M. d. S. Fernandes, S. R. Georgetti, and E. I. Ida, "Parameters of the fermentation of soybean flour by Monascus purpureus or Aspergillus oryzae on the production of bioactive compounds and antioxidant activity," Food Chemistry, vol. 271, pp. 274-283, 2019.

[41] A. Ramesha and C. Srinivas, "Antimicrobial activity and phytochemical analysis of crude extracts of endophytic fungi isolated from Plumeria acuminata L. and Plumeria obtusifolia L." European Journal of Experimental Biology, vol. 4, pp. 35-43, 2014.

[42] E. N. Danial, A. A. Khalil, W. A. El Khateeb, and G. E. Awad, "Assessment of phenolic content, free radical-scavenging capacity and antimicrobial activities of 28 marine filamentous fungi," Functional Plant Science and Biotechnology, vol. 5, pp. 83-87, 2011.

[43] K. Dajanta, P. Janpum, and W. Leksing, "Antioxidant capacities, total phenolics and flavonoids in black and yellow soybeans fermented by Bacillus subtilis: a comparative study of Thai fermented soybeans (thua nao)," International Food Research Journal, vol. 20, no. 6, p. 3125, 2013.

[44] M. L. Guzmán-Uriarte, L. M. Sánchez-Magaña, G. Y. AnguloMeza et al., "Solid state bioconversion for producing common bean (Phaseolus vulgaris L.) functional flour with high antioxidant activity and antihypertensive potential," Food and Nutrition Sciences, vol. 4, no. 4, pp. 480-490, 2013.

[45] Y. Plaitho, K. Kangsadalampai, and M. Sukprasansap, "The protective effect of Thai fermented pigmented rice on urethane induced somatic mutation and recombination in Drosophila melanogaster," Journal of Medicinal Plants Research, vol. 7, pp. 91-98, 2013.

[46] B. Moktan, J. Saha, and P. K. Sarkar, "Antioxidant activities of soybean as affected by Bacillus-fermentation to kinema," Food Research International, vol. 41, no. 6, pp. 586-593, 2008.

[47] A. E. A. Magro, L. C. Silva, G. B. Rasera, and R. J. S. de Castro, "Solid-state fermentation as an efficient strategy for the biotransformation of lentils: enhancing their antioxidant and antidiabetic potentials," Bioresources and Bioprocessing, vol. 6, p. 38, 2019.

[48] G. Oboh, A. Ademosun, S. Adefegha, and L. Lajide, "Enhancement of antioxidant properties and neuroprotective potentials of citrus peels using Aspergillus niger solid substrate fermentation technology," Fermentation Technology and Bioengineering, vol. 1, pp. 49-61, 2011.

[49] P. Chomcheon, S. Wiyakrutta, N. Sriubolmas et al., "Aromatase inhibitory, radical scavenging, and antioxidant activities of depsidones and diaryl ethers from the endophytic fungus Corynespora cassiicola L36," Phytochemistry, vol. 70, no. 3, pp. 407-413, 2009.

[50] K. Baert, "Pharmacokinetics and pharmacodynamics of nonsteroidal anti-inflammatory drugs in birds," $\mathrm{Ph}$. D. thesis, Ghent University, Ghent, Belgium, 2003.
[51] H. J. Al-Tameme, M. Y. Hadi, and I. H. Hameed, "Phytochemical analysis of Urtica dioica leaves by fourier-transform infrared spectroscopy and gas chromatography-mass spectrometry," Journal of Pharmacognosy and Phytotherapy, vol. 7, no. 10, pp. 238-252, 2015.

[52] M. Abubakar and R. Majinda, "GC-MS analysis and preliminary antimicrobial activity of Albizia adianthifolia (Schumach) and Pterocarpus angolensis (DC)," Medicines, vol. 3, no. 1, p. 3, 2016.

[53] C. Priyanka, P. Kumar, S. P. Bankar, and L. Karthik, "In vitro antibacterial activity and gas chromatography-mass spectroscopy analysis of Acacia karoo and Ziziphus mauritiana extracts," Journal of Taibah University for Science, vol. 9, no. 1, pp. 13-19, 2015.

[54] S. Thomas, C. S. Vieira, M. A. Hass, and L. B. Lopes, "Stability, cutaneous delivery, and antioxidant potential of a lipoic acid and $\alpha$-tocopherol codrug incorporated in microemulsions," Journal of Pharmaceutical Sciences, vol. 103, no. 8, pp. 2530-2538, 2014.

[55] J. Wang, H. Liu, H. Gao et al., "Antimicrobial and antioxidant activities of the flower essential oil of Halimodendron halodendron," Natural Product Communications, vol. 6, pp. 1749-1753, 2011.

[56] M. M. Mostafiz, P. K. Jhan, J.-K. Shim, and K.-Y. Lee, "Methyl benzoate exhibits insecticidal and repellent activities against Bemisia tabaci (Gennadius) (Hemiptera: aleyrodidae)," PloS One, vol. 13, Article ID e0208552, 2018.

[57] J. Chen, T. Rashid, G. Feng, Y. Feng, A. Zhang, and M. J. Grodowitz, "Insecticidal activity of methyl benzoate analogs against red imported fire ants, Solenopsis invicta (Hymenoptera: formicidae)," Journal of Economic Entomology, vol. 112, no. 2, pp. 691-698, 2018.

[58] S. Save, R. Lokhande, and A. Chowdhary, "Determination of 1, 2-Benzenedicarboxylic acid, bis (2-ethylhexyl) ester from the twigs of Thevetia peruviana as a Colwell Biomarker," Journal of Innovations in Pharmaceuticals and Biological Sciences, vol. 2, no. 3, pp. 349-362, 2015.

[59] O. Wintola and A. Afolayan, "Chemical constituents and biological activities of essential oils of Hydnora africana thumb used to treat associated infections and diseases in South Africa," Applied Sciences, vol. 7, no. 5, p. 443, 2017.

[60] S. F. Asghar and M. Choudahry, "Gas chromatography-mass spectrometry (GC-MS) analysis of petroleum ether extract (oil) and bio-assays of crude extract of Iris germanica," International Journal of Genetics and Molecular Biology, vol. 3, pp. 95-100, 2011.

[61] A. M. Shahin, M. K. McGuire, N. Anderson, J. Williams, and M. A. McGuire, "Effects of margarine and butter consumption on distribution of trans-18:1 fatty acid isomers and conjugated linoleic acid in major serum lipid classes in lactating women," Lipids, vol. 41, no. 2, pp. 141-147, 2006.

[62] K. H. V. Merlin, K. Manickavasakam, and S. Mohan, "GC-MS analysis of bioactive components of a siddha poly herbal drug Adathodai chooranam," International Journal of Research in Ayurveda \& Pharmacy, vol. 7, no. 2, pp. 4-7, 2016. 